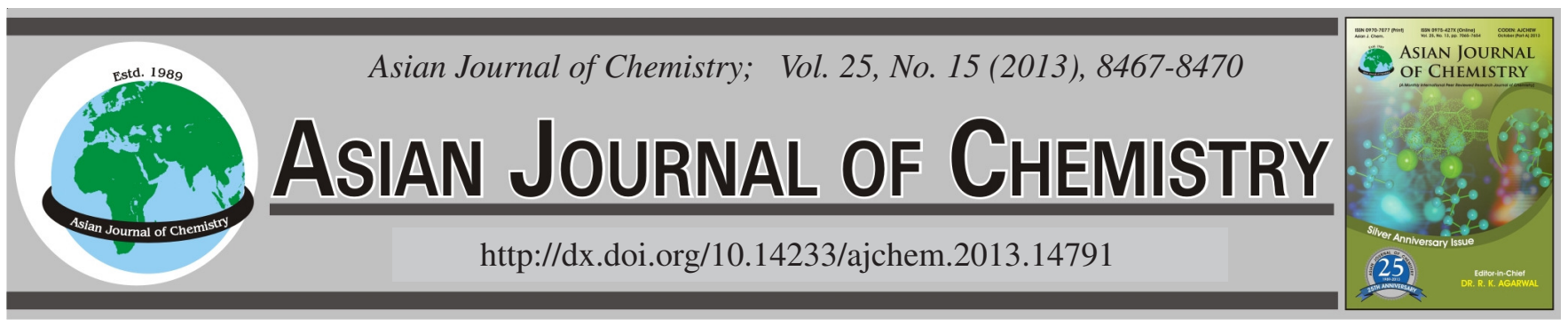

\title{
HPLC Based Metabolic Profiling of Rhizopus oryzae for Fumaric Acid Production Using Ammonia as a Neutralizing Agent
}

\author{
Chunzhen Shi ${ }^{1}$, Hongman Zhang ${ }^{2}$, Shuang $\mathrm{Li}^{1}$, Hongbo Zheng ${ }^{2}$, Qing Xu' ${ }^{1}$ and He Huang ${ }^{1 * *}$
}

${ }^{1}$ College of Biotechnology and Pharmaceutical Engineering, Nanjing University of Technology, Nanjing 210009, P.R. China

${ }^{2}$ College of Science, Nanjing University of Technology, Nanjing 210009, P.R. China

*Corresponding author: E-mail: chunzhenfighting@ sina.com

(Received: 7 November 2012;

Accepted: 24 August 2013)

AJC-13975

\begin{abstract}
In a typical fumaric acid fermentation with Rhizopus oryzae, the presence of a neutralizing agent is required. In this work, metabolic profiling of $R$. oryzae for fumaric acid production by fermentation using ammonia as a neutralizing agent was carried out by HPLC. Principle component analysis was employed to classify HPLC data of $R$. oryzae fermentation. The variations of intracellular metabolites, i.e., cAMP, ATP, NADH and alanine were measured by HPLC. The results showed fumaric acid production by fermentation with $R$. oryzae using ammonia as a neutralizing agent can be divided into two phases: the former fermentation phase and the latter fermentation phase. ATP, NADH, cAMP and alanine were the biomarkers. ATP, NADH, cAMP positively correlated to fumaric acid yield, whereas alanine had negative correlation to fumaric acid yield.
\end{abstract}

Key Words: Fumaric acid, Rhizopus oryzae, Metabolic profiling, Fermentation, HPLC.

\section{INTRODUCTION}

Fumaric acid is known as (E)-2-butenedioic acid or trans1,2-ethylenedicarboxylic acid, which is a naturally occurring organic acid. Because of its structure (a carbon-carbon double bond and two carboxylic acid groups), fumaric acid has many potential industrial applications to produce maleic acid, succinic acid, paper resins, food and beverage additives, miscellaneous, unsaturated polyester resins and alkyd resins ${ }^{1}$. After the discovery of fumaric acid production in Rhizopus nigricans by Foster and Waksman ${ }^{2} \&$ Foster et al. $^{3}$ screened 41 strains from eight different genera to identify high fumarate producing strains. The fumarate producing genera identified were Rhizopus, Mucor, Cunninghamella and Circinella species. Among these strains, Rhizopus species (nigricans, arrhizus, oryzae and formosa) were the best-producing ones, yielding fumaric acid under aerobic and anaerobic conditions ${ }^{3-7}$. The $R$. arrhizus NRRL 2582 and $R$. oryzae ATCC 20344 gave the highest volumetric productivity, product titer and product yield values $^{8,9}$.

In the process of fumaric acid fermentation, calcium carbonate was usually used as the neutralizing agent to adjust the $\mathrm{pH}$. While a relatively high yield of fumaric acid of 30-50 $\mathrm{g} / \mathrm{L}$ was achieved ${ }^{10}$. The addition of inorganic acid in the extraction process would result in a large number of solid waste, which is not environmentally friendly. The utilization of ammonia as a neutralizing agent can avoid this problem, since ammonium fumarate produced in the fermentation process can be concentrated as a raw material and used directly in the production of L-aspartic acid. Therefore, fumaric acid fermentation using ammonia as a neutralizing agent is a cleaner production process. However, with ammonia as the neutralizing agent, the yield of fumaric acid is comparatively low (ca. $20 \mathrm{~g} / \mathrm{L}$ ). In order to analyze the accumulation mechanism of fumaric acid in $R$. oryzae with ammonia as the neutralizing agent, HPLC was performed to detect the intracellular fumaric acid, amino acids, energy carriers at different fermentation time. And PLS-DA was applied for metabolic profiling analysis. The effects of four biomarkers on fumaric acid yield were also discussed.

\section{EXPERIMENTAL}

A Summit HPLC system from Dionex (USA) combined with a P680 pump, an autosampler, a UVD-170 UV/VIS Detector, a TCC2100 oven, 8125 type of injection device and work station (Dionex Chromeleon system) was used for analysis. 580R low-temperature centrifuge (Eppendorf Company), MDF-U32V Freezer at $-80^{\circ} \mathrm{C}$ (Japan SANYO) and RE-52A rotary evaporator (YaRong biochemical Instrument Factory, Shanghai, China) were also employed.

Microorganism and medium: The industrial strain MEF12 (R. oryzae ME-F12) was used throughout this work. The 
composition of the pre-culture medium ( $\mathrm{g} / \mathrm{L}$ ) was as follows: xylose or glucose $40 \%, \mathrm{KH}_{2} \mathrm{PO}_{4} 0.1 \% \mathrm{MgSO}_{4} 0.5 \% \mathrm{ZnSO}_{4}$ $0.0176 \% \mathrm{FeSO}_{4} 0.00498 \%, \mathrm{pH} 2.4$.

The production broth had the following composition: glucose $40 \%$, urea $0.2 \%, \mathrm{KH}_{2} \mathrm{PO}_{4} 0.1 \%, \mathrm{MgSO}_{4} 0.5 \%$, $\mathrm{ZnSO}_{4} 0.0176 \%, \mathrm{FeSO}_{4} 0.00498 \%$, with other ingredients similar as the pre-culture medium.

Ammonia was employed in the pre-culture medium as a neutralizing agent in fumaric acid production medium. The initial $\mathrm{pH}$ for the pre-culture medium was 4 .

The cultivations of the microorganisms were conducted in conical flasks $(250 \mathrm{~mL})$ in a rotary shaker at $35^{\circ} \mathrm{C}$. Some of the flasks were provided with polyurethane foams in a form of a ring ( $8 \mathrm{~cm}$ in diameter; $1 \mathrm{~cm}$ in thickness) in order to immobilize the microorganism. Simultaneously, under the same conditions, control cultivations with free cells were conducted.

Culture method: Pre-culture and fumaric acid production brothes were carried out in a $250 \mathrm{~mL}$ flask with $50 \mathrm{~mL}$ medium at $200 \mathrm{rpm}$ and at $35^{\circ} \mathrm{C}$. Nutrients and sugar solutions were autoclaved separately. Growth was carried out at $35^{\circ} \mathrm{C}$ and $200 \mathrm{rpm}$ in a gyratory incubator-shaker for $30 \mathrm{~h}$. After cultivation, the mycelial pellets were harvested by filtration and transferred into a fermentor containing production medium. Sterile ammonia was added whenever needed to maintain the $\mathrm{pH}$ at 4 . The fermentation was operated with an aeration rate of $2 \mathrm{~L} / \mathrm{min}$ at $35^{\circ} \mathrm{C}$ and $400 \mathrm{rpm}$ for $84 \mathrm{~h}$. Dissolved oxygen was not controlled, nor was it monitored. Samples were taken periodically per $12 \mathrm{~h}$ for HPLC analysis.

Quenching and extraction: $R$. oryzae was quenched according to the described method ${ }^{11}$. Unless otherwise stated, the samples were quenched in triplicate at OD600 $=6.0$ (middle exponential phase). Samples of culture $(10 \mathrm{~mL})$ were quickly harvested with a $5 \mathrm{~mL}$ automated Gilson pipette and released into $20 \mathrm{~mL}$ methanol-water solution $(60 \% \mathrm{v} / \mathrm{v})$ at $-80{ }^{\circ} \mathrm{C}$, resulting in a final methanol concentration of $50 \%(\mathrm{v} / \mathrm{v})$ after quenching. The samples were carefully released into the center of the methanol solution to avoid freezing on the sides of the tubes. The biomass was separated from the quenching solution by centrifugation at $6000 \times \mathrm{g}$ for $3 \mathrm{~min}$ at $-10^{\circ} \mathrm{C}$.

For evaluation of the quenching procedure, we quenched $10 \mathrm{~mL}$ samples and released them into $10 \mathrm{~mL}$ of $60 \%(\mathrm{v} / \mathrm{v})$ cold methanol solution. The biomass was separated from the quenching solution by centrifugation at $6000 \times \mathrm{g}$ for $3 \mathrm{~min}$ at $-10{ }^{\circ} \mathrm{C}$ according to the original protocol. A faster biomass separation from the quenching medium was also tested by centrifugation at $6000 \times \mathrm{g}$ for $3 \mathrm{~min}$ at $-10^{\circ} \mathrm{C}$.

Method for extraction of intracellular metabolites: The biomass was resuspended in $2.5 \mathrm{~mL} 100 \%(\mathrm{v} / \mathrm{v})$ cold methanol solution $\left(-80^{\circ} \mathrm{C}\right)$ after quenching and the mixture was frozen in an ultra low temperature refrigerator. The frozen suspension was then thawed in an ice-bath under $4{ }^{\circ} \mathrm{C}$ and mixed for 1 min. The supernatant was collected and an additional $2.5 \mathrm{~mL}$ of $100 \%(\mathrm{v} / \mathrm{v})$ cold methanol solution $\left(-40^{\circ} \mathrm{C}\right)$ was added to the pellet and shaken manually for $30 \mathrm{~s}$ using a vortex mixer. The mixture was centrifuged at $6000 \times \mathrm{g}$ for $3 \mathrm{~min}$ at $-10^{\circ} \mathrm{C}$ and both supernatants were pooled and lyophilized at $-80^{\circ} \mathrm{C}$.

\section{Analytical methods}

Analysis of extracellular fumaric acid, residual glucose and biomass: Fumaric acid was quantified by HPLC as reported by Zhou et al. ${ }^{12}$. The final culture broth was diluted by addition of water and diluted $\mathrm{HCl}$ was added to neutralize the excess ammonia. The broth was heated at $80^{\circ} \mathrm{C}$ until it was clear, then the supernatant was collected for analysis. A Dionex HPLC equipped with a refractive index detector was employed, the mobile phase was $5 \mathrm{mM} \mathrm{H}_{2} \mathrm{SO}_{4}$ at a flow rate of $0.8 \mathrm{~mL}$ $\mathrm{min}^{-1}$ through a Bio-Rad Aminex HPX-87H column at $60^{\circ} \mathrm{C}$.

Sugars were determined and quantified by HPLC as reported $^{13}$ : xylose and glucose were analyzed by HPLC (Dionex) equipped with a Bio-Rad Aminex HPX-87P column and a refractive index detector. The mobile phase was water at a flow rate $0.6 \mathrm{~mL} \mathrm{~min}{ }^{-1}$ and column temperature was $85^{\circ} \mathrm{C}$.

Biomass was measured by washing the mycelia twice with distilled water, drying at $70^{\circ} \mathrm{C}$ until constant weight was achieved.

Analysis of intracellular amino acids, energy carriers: Amino acids were quantified by HPLC as reported by Shi et $a l .{ }^{14}$.

The standards solution of amino acids and energy carriers standards were purchased from Sigma. Acetonitrile and methanol were of HPLC grade and obtained from J.T. Baker (Deventer, Holland); high-purity water was supplied by Mili-Q plus system from Milipore Corp. (Bedford, MA, USA). Triethylamine, Hexane and Glacial acetic acid were of analytical pure grade. An ultra low temperature refrigerator which could reach $-80^{\circ} \mathrm{C}$ was used.

Data handling and quantification were done with Chromeleon (Dionex, USA). The raw data were analyzed by Chromeleon (Dionex, USA) for peak detection and alignment. LC experimental conditions for amino acids analysis were shown in Table-1. Energy carriers were analyzed by HPLC ${ }^{15}$ and the HPLC experimental conditions were shown in Table-2.

\begin{tabular}{|c|c|}
\hline & $\begin{array}{c}\text { TABLE-1 } \\
\text { HPLC EXPERIMENTAL CONDITIONS } \\
\text { FOR AMINO ACIDS ANALYSIS }\end{array}$ \\
\hline Column & Sepax $C_{18}$ column $(250 \mathrm{~mm} \times 4.6 \mathrm{~mm} \times 5 \mu \mathrm{m})$ \\
\hline $\begin{array}{l}\text { Mobile } \\
\text { phase }\end{array}$ & $\begin{array}{l}\text { A, } 0.1 \mathrm{~mol} / \mathrm{L} \text { sodium acetate }: \text { acetonitrile } 97: 3(\mathrm{v}: \mathrm{v}) \mathrm{B} \text {, } \\
\text { acetonitrile : water } 4: 1(\mathrm{v}: \mathrm{v})\end{array}$ \\
\hline $\begin{array}{l}\text { Mobile } \\
\text { phase } \\
\text { program }\end{array}$ & $\begin{array}{l}0 \% \mathrm{~B} \text { to } 7 \% \mathrm{~B} \text { at } 1 \% \min ^{-1}, 7 \% \mathrm{~B} \text { to } 9 \% \mathrm{~B} \text { at } 0.25 \% \\
\min ^{-1}, 9 \% \mathrm{~B} \text { to } 27 \% \mathrm{~B} \text { at } 3 \% \mathrm{~min}^{-1}, 27 \% \mathrm{~B} \text { to } 33 \% \mathrm{~B} \\
\text { at } 0.7 \% \mathrm{~min}^{-1}, 33 \% \mathrm{~B} \text { to } 100 \% \mathrm{~B} \text { at } 6700 \% \mathrm{~min}^{-1}, 100 \\
\% \mathrm{~B} \text { held for } 10 \mathrm{~min}, 100 \% \mathrm{~B} \text { to } 0 \% \mathrm{~B} \text { at } 20 \% \mathrm{~min}^{-1} \text {, } \\
0 \% \mathrm{~B} \text { held for } 5 \mathrm{~min}\end{array}$ \\
\hline $\begin{array}{l}\text { Operation } \\
\text { conditions }\end{array}$ & $\begin{array}{l}\text { injection volume, } 20 \mu \mathrm{L} \text {; column temperature, } 36{ }^{\circ} \mathrm{C} \text {; } \\
\text { detection wavelength, } 254 \mathrm{~nm} \text {; flow rate, } 1 \mathrm{~mL} / \mathrm{min}\end{array}$ \\
\hline
\end{tabular}

TABLE-2

LC EXPERIMENTAL CONDITIONS FOR THE ANALYSIS OF ENERGY CARRIERS (ATP, ADP, NADP, NADPH, AMP, cAMP)

Column $\quad$ Sepax HP- $\mathrm{C}_{18}$ column $(250 \mathrm{~mm} \times 4.6 \mathrm{~mm} \times 5 \mu \mathrm{m})$

Mobile phase A, $0.6 \%(\mathrm{v} / \mathrm{v})$ phosphate, $\mathrm{pH}$ adjusted to 6.6 with triethylamine $\mathrm{B}$, methanol

Mobile phase $10 \% \mathrm{~B}$ held for $10 \mathrm{~min}, 10 \% \mathrm{~B}$ to $25 \% \mathrm{~B}$ at $3 \%$ program $\min ^{-1}, 25 \% \mathrm{~B}$ held for $25 \mathrm{~min}$

Operation Injection volume, $20 \mu \mathrm{L}$; column temperature, $25^{\circ} \mathrm{C}$; conditions detection wavelength, $254 \mathrm{~nm}$; flow rate, $1 \mathrm{~mL} / \mathrm{min}$ 


\section{RESULTS AND DISCUSSION}

Metabolic profiling of $R$. oryzae during fermentation: HPLC was applied to detect the intracellular metabolites of $R$. oryzae during fermentation. There were 25 intracellular metabolites identified and quantified, including 18 amino acids, fumaric acid and 6 energy carriers.

Multivariate data analysis: Multivariate data analysis was performed by partial least squares-discriminant analysis (PLS-DA), which had been successfully applied to many kinds of data sets ${ }^{16,17}$. In the PLS-DA scores plot (Fig. 1b), each data point represented a linear combination of all the metabolites from each individual sample. In the PLS-DA loading plot (Fig. 1a), each data point represented a mass fragment of a certain metabolite. The farther a data point was from the origin, the greater the component it belonged to influenced the cluster formation.

As shown in Fig. 1, the metabolic profiling of $R$. oryzae using ammonia as a neutralizing agent was analyzed by PLSDA.

The scores plot showed that samples could be clearly separated into group A and group B (Fig. 1b), indicating that industrial $R$. oryzae displayed distinct metabolic characteristics under different fermentation stages. For the fermentation process, samples from fermenters 1-4 and 5-8 formed two distinct groups, i.e., the former fermentation phase (group A) and the latter fermentation phase (group B).

As shown in the loading plot, ATP, NADH, cAMP and alanine were found to make great contribution for distinguishing different fermentation phases of samples. Metabolites associated with glycolysis pathway (lactic acid, glycerol), intermediates of TCA cycle (citrate and malate) as well as amino acids (glycine and glutamine) contributed to the cluster formation most significantly.

Variations of intracellular metabolites: cAMP, ATP, NADH and alanine: As shown in Fig. 2, the intracellular metabolites ATP, cAMP, NADH accumulated mainly during $0-36 \mathrm{~h}$ (the former fermentation phase), whereas they decreased during 36-70 $\mathrm{h}$ (the latter fermentation phase).

Fig. 3 showed the level of fumaric acid increased dramatically during the former fermentation phase and remained relatively stable during the latter fermentation phase.

ATP, NADH, cAMP accumulated mainly during the former fermentation phase, but decreased during the latter fermentation phase, which was consistent with the trend of variation of fumaric acid yield (Figs. 2 and 3). It was likely that during the former fermentation phase, the accumulation of ATP, NADH and cAMP increased the efficiency of the TCA cycle in $R$. oryzae, providing more energy for the synthesis and transport of fumaric acid. Or the other way around, while the acid production rate increased, fumaric acid massively accumulated intracellularly, requiring more energy to be transported extracellularly, which resulted in the increase of energy carriers (Fig. 4).

The trend of variation of alanine was in contrast with that of fumaric acid in the whole fermentation phase. It decreased in the former fermentation phase and increased in the latter fermentation phase. Thus during the fermentation process, accumulation of alanine or its exogenous addition should be avoided.
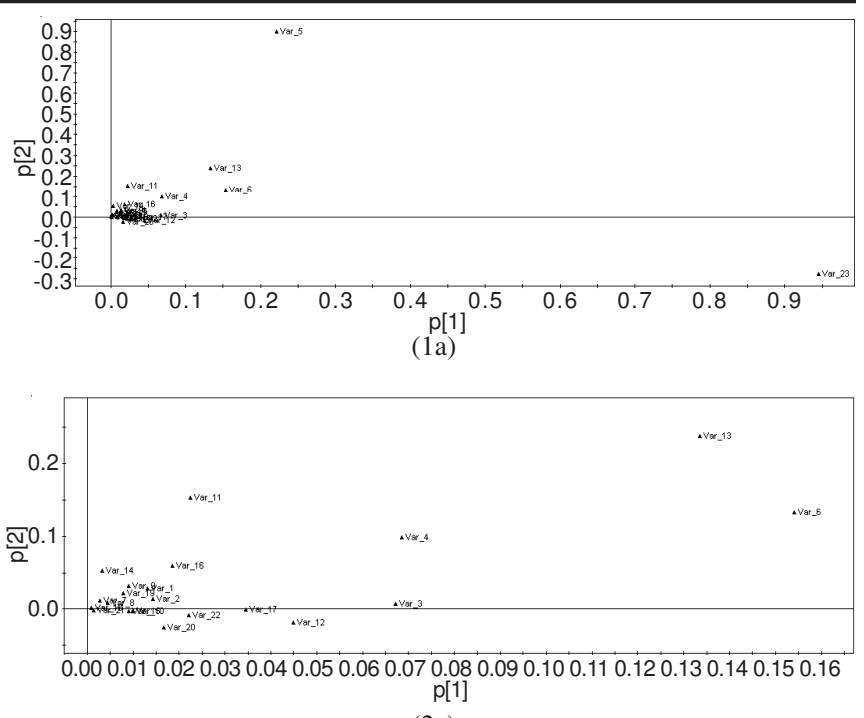

(2a)

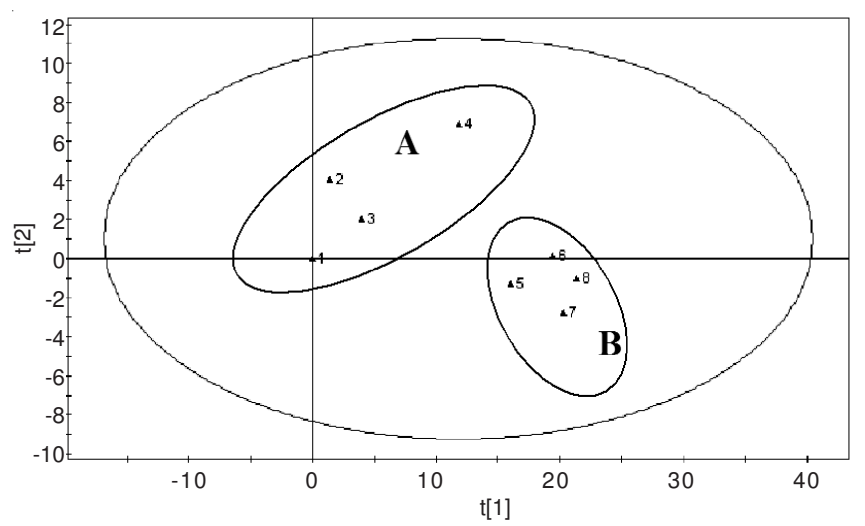

(b)

\begin{tabular}{|c|c|c|c|}
\hline \multicolumn{4}{|c|}{ Var 1-Var 23 in Fig. 1a } \\
\hline Var 1 & NAD & Var 13 & Ala \\
\hline Var 2 & AMP & Var 14 & Tyr \\
\hline Var 3 & $\mathrm{ADP}$ & Var 15 & Val \\
\hline Var 4 & ATP & Var 16 & Met \\
\hline Var 5 & cAMP & Var 17 & Cys \\
\hline Var 6 & NADH & Var 18 & Ile \\
\hline $\operatorname{Var} 7$ & Glu & Var 19 & Try \\
\hline Var 8 & Ser & Var 20 & Phe \\
\hline Var 9 & Gly & Var 21 & Lys \\
\hline Var 10 & His & Var 22 & Intracellular FA \\
\hline Var 11 & Arg & Var 23 & Extracellular FA \\
\hline Var 12 & Thr & - & - \\
\hline \multicolumn{4}{|c|}{ 1-8 in Fig. $1 b$} \\
\hline $\mathrm{Se}$ & re of $19 \mathrm{~h}$ & 5 & Fermentation of $36 \mathrm{~h}$ \\
\hline 2 & ion of $0 \mathrm{~h}$ & 6 & Fermentation of $48 \mathrm{~h}$ \\
\hline $\mathrm{Fe}$ & on of $12 \mathrm{~h}$ & 7 & Fermentation of $60 \mathrm{~h}$ \\
\hline $\mathrm{Fe}$ & on of $24 \mathrm{~h}$ & 8 & Fermentation of $70 \mathrm{~h}$ \\
\hline
\end{tabular}

Fig. 1. PLS-DA results of samples. (a) loading plot; (b) scores plot

\section{Conclusion}

The intracellular amino acids, fumaric acid and energy carriers of $R$. oryzae at different fermentation time were determined by HPLC using ammonia as a neutralizing agent. PLS-DA was performed to analyze the metabolic profiling of $R$. oryzae at different fermentation time. The results showed that the fermentation process of $R$. oryzae using ammonia as a neutralizing agent can be divided into the former fermentation 


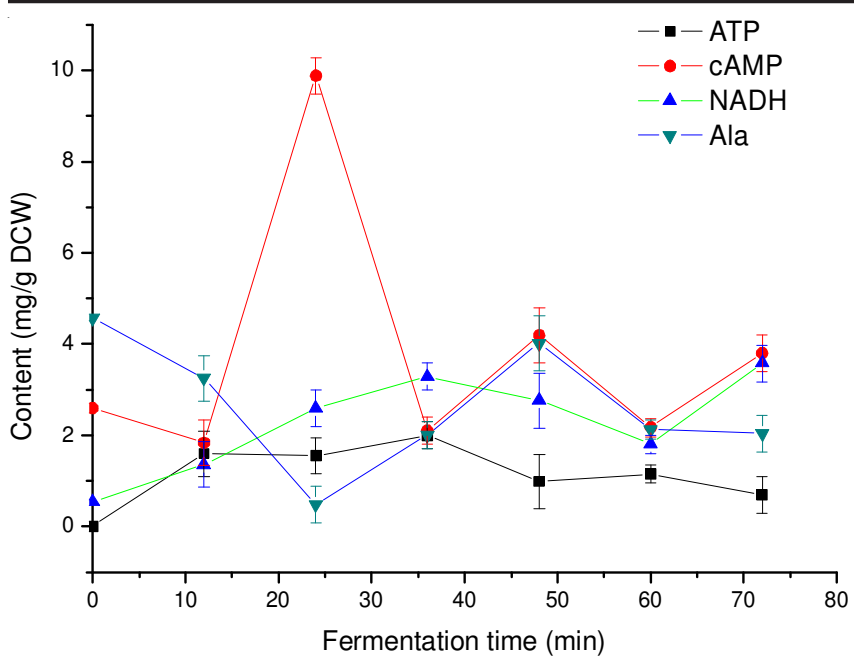

Fig. 2. Variations of ATP, cAMP, NADH and alanine contents at different fermentation time

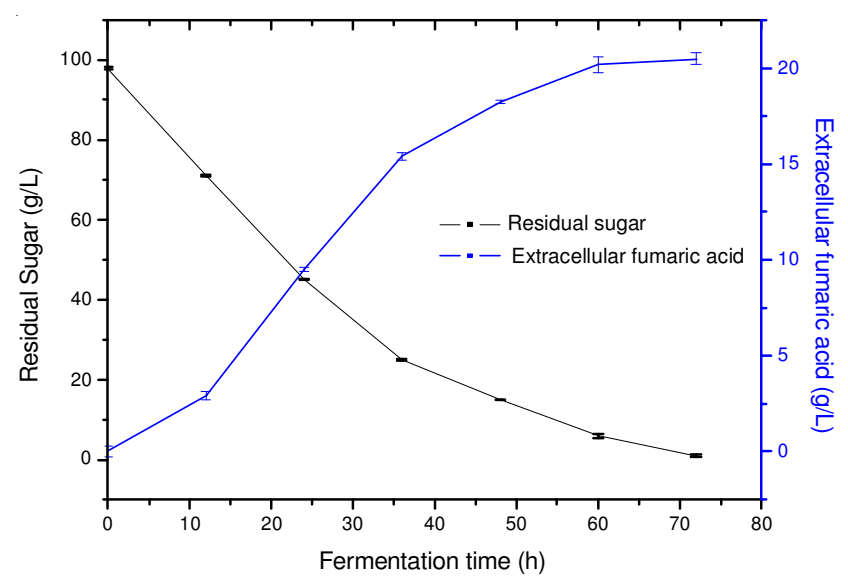

Fig. 3. Variations of residual sugar and extracellular fumaric acid contents at different fermentation time

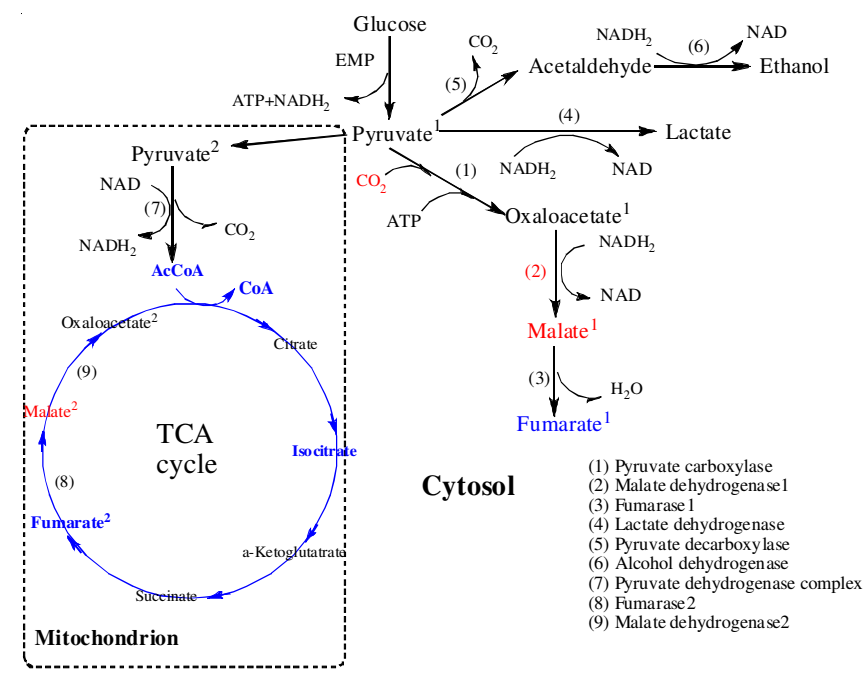

Fig. 4. Citrate cycle pathway and reductive carboxylation pathway leading to fumaric acid accumulation phase and the latter fermentation phase. And the ATP, NADH, cAMP and alanine were the biomarkers. ATP, NADH and cAMP positively correlated to fumaric acid yield, which indicated the accumulation of ATP, NADH and cAMP increased the efficiency of the TCA cycle in $R$. oryzae, providing more energy for the synthesis and transport of fumaric acid. Or the other way around, while the acid production rate increased, fumaric acid massively accumulated intracellularly, requiring more energy to be transported extracellularly, which resulted in the increase of energy carriers. However, alanine had a negative correlation with fumaric aicd yield. Thus during the fermentation process, accumulation of alanine or its exogenous addition should be avoided.

\section{REFERENCES}

1. T. Willke and K.-D. Vorlop, Appl. Microbiol. Biotechnol., 66, 131 (2004).

2 J.W. Foster and S.A. Waksmann, J. Am. Chem. Soc., 61, 127 (1938).

3 J.W. Foster, S.F. Carson, D.S. Anthony, J.B. Davis, W.E. Jeffersona nd M.V. Long, Proc. Nat. Acad. Sci. USA, 35, 663 (1949).

4 R.A. Rhodes, A.A. Lagoda, R.W. Jackson, T.J. Misenhei, M.L. Smith and R.F. Anderson, Appl. Microbiol., 10, 9 (1962).

5 W. Kenealy, E. Zaady, J.C. Dupreez, B. Stieglitz and I. Goldberg, Appl. Environ. Microbiol., 52, 128 (1986).

6 N.J. Cao, J.X. Du, C.S. Gong and G.T. Tsao, Appl. Biochem. Biotechnol., 63, 387 (1997).

7 F.S. Carta, C.R. Soccol, L.P. Ramos and J.D. Fontana, Bioresour. Technol., 68, 23 (1999).

8 I.C. Gangl, W.A. Weigand and F.A. Keller, Appl. Biochem. Biotechnol., 24-25, 663 (1990).

9 N.J. Cao, J.X. Du, C.A. Gong and G.T. Tsao, Appl. Environ. Microbiol., 62, 2926 (1996).

10 Z. Gao, K. Zhang, H. Huang, S. Li and P. Wei, Prog. Chem., 21, 251 (2009).

11 A.B. Canelas, C. Ras, A. ten Pierick, J.C. van Dam, J.J. Heijnen and W.M. van Gulik, Metabolomics, 4, 226 (2008).

12 Y. Zhou, J.X. Du and G.T. Tsao, Appl. Biotechnol., 84-86, 779 (2000).

13 L.S. Yan, H.M. Zhang, J.W. Chen, Z.X. Lin, Q. Jin, H.H. Jia and H. Huang, Bioresour. Technol., 100, 1803 (2009).

14 C.Z. Shi, H.M. Zhang, H. Huang, S. Li, P. Song and S.L. He, Chin. J. Anal. Chem., 40, 574 (2012).

15 M. Ganzera, P. Vrabl, E. Wörle, W. Burgstaller and H. Stuppner, Anal. Chem., 359, 132 (2006).

16 P. Jonsson, A.I. Johansson, J. Gullberg, J. Trygg, A. Jiye, B. Grung, S. Marklund, M. Sjostrom, H. Antti and T. Moritz, Anal. Chem., 77, 5635 (2005).

17 P.P. Han and Y.J. Yuan, FASEB J., 23, 623 (2009). 